\title{
Assessment of MR Imaging and CT in Differentiating Hereditary and Nonhereditary Paragangliomas
}

\author{
(D). Ota, (D). Naganawa, (D). Kurokawa, (D).R. Bapuraj, (D)A. Capizzano, (D). Kim, (D). Moritani, and (D) A. Srinivasan
}

\begin{abstract}
BACKGROUND AND PURPOSE: Head and neck paragangliomas have been reported to be associated with mutations of the succinate dehydrogenase enzyme family. The aim of this study was to assess whether radiologic features could differentiate between paragangliomas in the head and neck positive and negative for the succinate dehydrogenase mutation.
\end{abstract}

MATERIALS AND METHODS: This single-center retrospective review from January 2015 to January 2020 included 40 patients with 48 paragangliomas (30 tumors positive for succinate dehydrogenase mutation in 23 patients and 18 tumors negative for the succinate dehydrogenase mutation in 17 patients). ADC values and tumor characteristics on CT and MR imaging were evaluated by 2 radiologists. Differences between the 2 cohorts in the diagnostic performance of ADC and normalized ADC (ratio to ADC in the medulla oblongata) values were evaluated using the independent samples $t$ test. $P<.05$ was considered significant.

RESULTS: $A D C_{\text {mean }}\left(1.07[\mathrm{SD}, 0.25] / 1.04[\mathrm{SD}, 0.12]\right.$ versus $1.31[\mathrm{SD}, 0.16] / 1.30[\mathrm{SD}, 0.20] \times 10^{-3} \mathrm{~mm}^{2} / \mathrm{s}$ by radiologists 1 and $\left.2 ; P<.001\right)$, $\mathrm{ADC}_{\text {maximum }}\left(1.49[\mathrm{SD}, 0.27] / 1.49[\mathrm{SD}, 0.20]\right.$ versus $\left.2.01[\mathrm{SD}, 0.16] / 1.87[\mathrm{SD}, 0.20] \times 10^{-3} \mathrm{~mm}^{2} / \mathrm{s} ; P<.001\right)$, normalized $\mathrm{ADC}$ mean $(1.40[\mathrm{SD}$, $0.33] / 1.37$ [SD, 0.16] versus 1.73 [SD, 0.22]/1.74 [SD, 0.27]; $P<.001$ ), and normalized ADC maximum (1.95 [SD, 0.37]/1.97 [SD, 0.27] versus 2.64 [SD, 0.22]/2.48 [SD, 0.28]; $P<.001$ ) were significantly lower in succinate dehydrogenase mutation-positive than mutation-negative tumors. $A D C_{\text {minimum, }}$ normalized $A D C_{\text {minimum }}$, and tumor characteristics were not statistically significant.

CONCLUSIONS: ADC is a promising imaging biomarker that can help differentiate succinate dehydrogenase mutation-positive from mutation-negative paragangliomas in the head and neck.

ABBREVIATIONS: $\mathrm{nADC}=$ normalized $\mathrm{ADC} ; \mathrm{SDH}=$ succinate dehydrogenase

D aragangliomas are uncommon neuroendocrine tumors with an estimated annual incidence of 3-8 cases per 1 million people in the general population. ${ }^{1}$ They arise from the sympathetic and parasympathetic autonomic system and occur anywhere from the base of the skull to the pelvis, with $70 \%$ of extra-adrenal paragangliomas arising in the head and neck region. The typical clinical sites are the carotid artery bifurcation, middle ear, and jugular fossa. ${ }^{1-3}$ Clinical manifestations include hypertension, palpitations, headache, excessive

Received November 17, 2020; accepted after revision February 15, 2021. From the Division of Neuroradiology (Y.O., S.N., J.R.B., A.C., J.K., T.M., A.S.), Department of Radiology, University of Michigan, Ann Arbor, Michigan; and Department of Radiology (R.K.), Graduate School of Medicine, The University of Tokyo, Tokyo, Japan.

Please address correspondence to Yoshiaki Ota, MD, 1500 E Medical Center Dr, UH B2, Ann Arbor, Ml 48109; e-mail: yoshiako@med.umich.edu

- Indicates open access to non-subscribers at www.ajnr.org

Indicates article with online supplemental data.

http://dx.doi.org/10.3174/ajnr.A7166 sweating, and pallor, which vary depending on the tumor size, location, and biochemical activity. ${ }^{1,4}$

There has been an increasing interest in the genetic basis for paragangliomas. Although head and neck paragangliomas often occur as sporadic tumors, it is now recognized that approximately $30 \%-40 \%$ of head and neck paragangliomas are associated with autosomal dominant hereditary tumor syndromes. ${ }^{1,2,5}$ Succinate dehydrogenase (SDH), a multiprotein complex composed of SDH subunit A, B, C, and D proteins, is an important enzyme in the Krebs cycle and electron transport chain in the mitochondria for energy production. The loss of SDH function results in less efficiency of these processes. Moreover, these altered pathways allow the tumor cells to grow even in a low-oxygen environment. ${ }^{6}$ Therefore, deactivation in any of the subunits will result in tumors positive for the $S D H$ mutation.

Familial paraganglioma syndromes associated with $S D H$ gene mutations have now been recognized as the primary cause of hereditary paragangliomas in the head and neck. Twenty-five percent of all paragangliomas and pheochromocytomas are related 
to genetic mutations in different subunits of the SDH protein, each with different tendencies toward different tumor locations, different numbers of lesions, and different potentials for malignancy. ${ }^{1}$ For example, familial paragangliomas with $S D H$ subunit $D(S D H D)$ mutation are more likely to be multifocal in the head and neck, and paragangliomas with $S D H$ subunit $B(S D H B)$ mutations are prone to malignant transformation. ${ }^{1}$ Therefore, establishment of genetic screening of individuals and life-long surveillance of patients at high risk for developing paragangliomas are important.

The typical imaging appearances of head and neck paragangliomas on CT and MR imaging include well-circumscribed lesions showing avid contrast enhancement. ${ }^{7-9}$ Prior studies have demonstrated that DWI and ADC parameters can be used for diagnosis, staging, and follow-up of head and neck tumors. ${ }^{10}$ As for paragangliomas, ADC values have been used in the past to differentiate these tumors from other head and neck lesions, with variable results. ${ }^{11}$ Because paragangliomas can have genetic mutations and a variety of histologic patterns, ${ }^{12}$ the variability of ADC values on MR imaging studies may be secondary to the heterogeneous genotype of these lesions. The aim of our study, therefore, was to evaluate the differences in ADC values between SDH mutation-positive and SDH mutation-negative head and neck paragangliomas to assess the utility of ADC as an imaging biomarker.

\section{MATERIALS AND METHODS}

The institutional review board of University of Michigan approved this retrospective single-center study and waived the requirement for informed consent. Data were acquired in compliance with all applicable Health Insurance Portability and Accountability Act regulations.

\section{Study Population}

We retrospectively reviewed 579 consecutive patients from January 2015 to January 2020 who were suspected of having head and neck paragangliomas from head and neck CT/MR imaging findings and clinical information. Among them, 94 patients had been diagnosed with paragangliomas histopathologically or clinically by elevated plasma fractionated metanephrines or elevated 24-hour urinary fractionated metanephrines, findings of head and neck CT and MR imaging, and PET with 2-Deoxy-2- $\left[{ }^{18} \mathrm{~F}\right]$ fluoro-d-glucose integrated with CT or indium-111 ( $\left.{ }^{111} \mathrm{In}\right)$ pentetreotide SPECT. We excluded patients who had previously undergone an operation, had undergone radiation therapy, did not have pretreatment CT/MR imaging $(n=28)$, or did not have prior genetic testing for $S D H$ mutations $(n=26)$. Forty patients (49.3 [SD, 14.9] years of age; 9 men; 31 women) with 48 paragangliomas constituted the final study cohort.

\section{Genetic Testing}

Genetic testing was by the PGLNext panel (Ambry Genetics), which requires collecting blood or saliva samples by an appropriate kit. PGLNext analyzes 12 genes including SDHA, SDH subunits AF2 (SDHAF2), SDHB, SDHC, and SDHD. This test is designed and validated to detect $>99 \%$ of the gene mutations noted above.

This cohort was further divided into 2 groups: the $S D H$ mutation-positive group and $S D H$ mutation-negative group.
In the $S D H$ mutation-positive group, there were 30 paragangliomas in 23 patients (mutations of the $S D H$ subunits $A, B, C$, and $D$ were $n=2,8,5$ and 15 , respectively). Nineteen lesions were pathologically proved, and 11 lesions were clinically diagnosed. Three patients with the SDHD mutation had 2 lesions each, 1 patient with an SDHD mutation had 4 lesions, and 1 patient with an $S D H B$ mutation had 2 lesions.

In the $S D H$ mutation-negative group, there were 18 paragangliomas in 17 patients. Eleven lesions were pathologically proved, and 7 lesions were clinically diagnosed. One patient had 2 lesions.

\section{MR Imaging Acquisition}

MR imaging studies were acquired on multiple scanners including 1.5T scanners (Ingenia, $n=10$, and Achieva, $n=10$; Philips Healthcare; Signa Excite, $n=4$, and GoldSeal Signa HDxt, $n=4$; GE Healthcare) and $3 \mathrm{~T}$ scanners (Magnetom Vida, $n=5$; Siemens; and Ingenia, $n=15$; Philips Healthcare). MR imaging sequences and parameters were summarized in the Online Supplemental Data. These parameters were modified depending on the field strength and manufacturers.

\section{CT Acquisition}

Contrast-enhanced CT neck examinations were acquired on a multislice 64-detector CT scanners (HD 750; GE Healthcare) with the following scan parameters: $120-140 \mathrm{kV}$ (peak), 80$295 \mathrm{~mA}$, skull base to thoracic inlet, $125 \mathrm{~mL}$ of iopamidol (Isovue 300; Bracco). The parameters of neck CT were as follows: plane $=$ axial, $\mathrm{FOV}=96 \mathrm{~mm}$, section thickness $=$ $0.625 \mathrm{~mm}$, window level and width $=400$ and $3200 \mathrm{HU}$, phase $=45$ seconds, delayed phase.

\section{Image Analysis}

Conventional Imaging Analysis. Two board-certified neuroradiologists with 6 and 9 years of experience interpreted all radiologic images independently. They were blinded to the mutation status of the lesions. Both radiologists recorded the following metrics:

1. Maximum axial diameter of the tumor on postcontrast T1weighted images.

2. The presence of necrotic or cystic changes and salt-and-pepper appearance (flow voids) evaluated on T2-weighted and pre- and postcontrast T1-weighted images. These were recorded as binary variables (yes/no). Cystic changes were defined as nonenhancing, predominantly T1-hypointense and T2-hyperintense areas; necrotic changes, as nonenhancing, predominantly T1-hypointense and heterogeneously T2-hyperintense areas; and salt-and-pepper appearance, as nonenhancing T1-hypointense and T2-hypointense vessel structures within the tumors.

3. Erosions of adjacent bony structures evaluated on CT. The axial plane was used. These were recorded as binary variables (yes/no).

4. Glomus jugulare and glomus jugulotympanicum were classified into head lesions; and carotid body tumors and glomus vagale, into neck lesion as for location.

ADC Analysis. ADC maps were constructed by a monoexponential fitting model using the commercially available

AJNR Am J Neuroradiol 42:1320-26 Jul 2021 www.ajnr.org 1321 

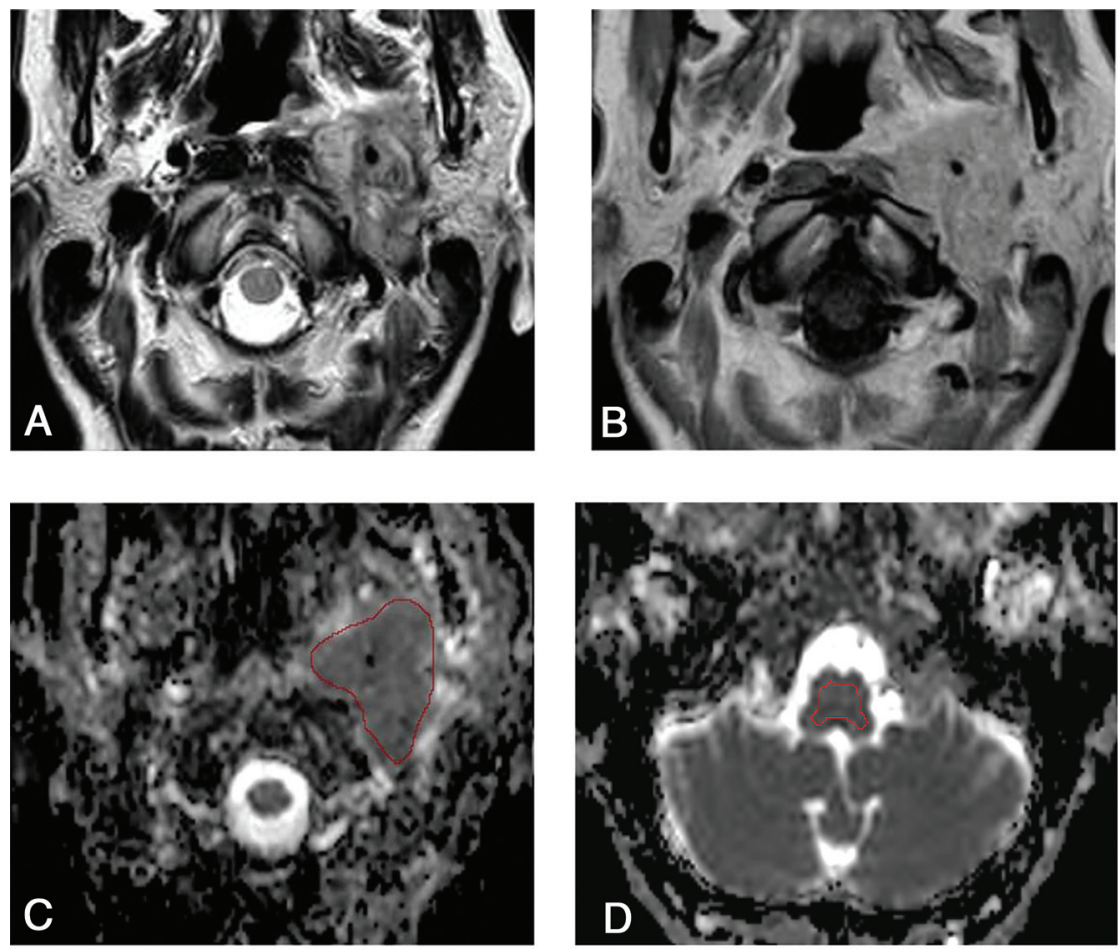

FIG 1. A 48-year-old woman positive for the SDHC mutation with a paraganglioma in the left jugular foramen. $A$ and $B$, Axial T2-weighted and contrast-enhanced T1-weighted images demonstrate a heterogeneously enhancing, irregularly shaped tumor with flow voids in the left jugular foramen. $C$, An ROI is placed on the lesion on the ADC map. The mean ADC, maximum ADC, and minimum $A D C$ values of reader 1 are 1.06, 1.47, and $0.53 \times 10^{-3} \mathrm{~mm}^{2} / \mathrm{s}$, respectively. $D$, Another ROI for an internal standard is placed on the medulla as an internal control (mean ADC, $0.75 \times$ $10^{-3} \mathrm{~mm}^{2} / \mathrm{s}$ ). The mean $\mathrm{nADC}$, maximum $\mathrm{nADC}$, and minimum $\mathrm{nADC}$ are $1.41,1.96$, and $0.71 \times 10^{-3}$ $\mathrm{mm}^{2} / \mathrm{s}$, respectively.

software Olea Sphere (Olea Medical). The 2 neuroradiologists independently outlined the tumors on an axial postcontrast T1-weighted image and transposed the freehand ROI to the ADC map. The axial images that predominantly showed solid enhancing portions without cystic or necrotic areas on postcontrast T1-weighted images were selected. The ROIs spared the peripheral 2-mm margin of the lesions to avoid volume averaging (Fig $1 C$ ). ${ }^{13}$ When geometric distortion was observed, the location and size were adjusted on the ADC map so that the ROI could be included within the tumor. A separate ROI was placed in the center of the medulla oblongata at the level of the foramen of Lushcka as an internal reference standard (Fig 1D). ${ }^{14}$ A normalized ADC (nADC) ratio was calculated by dividing each ADC value of the lesion by the mean $\mathrm{ADC}$ value of the medulla oblongata.

\section{Statistical Analysis}

Patient demographic characteristics including sex (ratio of male to female) and age, number of lesions, tumor characteristics of maximum diameter of tumor, presence or absence of salt-andpepper appearance, location (ratio of head/neck legion), adjacent skull destructive changes, and necrotic changes were compared between the 2 groups. Age was compared by $t$ tests and was described as mean (SD). The maximum diameter of the tumor
$P<.05$ were considered statistically significant.

\section{RESULTS}

Patient demographics and tumor characteristics are shown in Table 1. Patients who were in the $S D H$ mutation-positive group were significantly younger than those in the $S D H$ mutation-negative group (43.9 [SD, 16.2] years versus 56.9 [SD, 10.7] years; $P=.007$ ).

In the $S D H$ mutation-positive group, 4 patients with $S D H D$ mutations had multiple lesions in the head and neck (1 with 4 lesions, 1 with 3 lesions, and 2 with 2 lesions each) and 1 patient with an SDHB mutation had 2 lesions. There were 13 head lesions (7 glomus jugulare and 6 glomus jugulotympanicum lesions), and 17 neck lesions (16 carotid body tumors and 1 glomus vagale) in this group.

In the $S D H$ mutation-negative group, there were 13 head lesions (12 glomus jugulare and 1 jugulotympanicum) and 5 neck lesions ( 5 carotid body tumors).

There were no significant differences between the 2 groups in the maximum diameter of tumor, the presence or absence of saltand-pepper appearance, adjacent skull erosions, necrotic changes, or location (ratio of head/neck region).

\section{Reader 1 Results}

$\mathrm{ADC}_{\text {mean }}\left(1.07\right.$ [SD, 0.25] versus $1.31[\mathrm{SD}, 0.16] \times 10^{-3} \mathrm{~mm}^{2} / \mathrm{s}$; $P<.001), \quad \mathrm{ADC}_{\text {maximum }}(1.49[\mathrm{SD}, 0.27]$ versus 2.01 [SD, 


\begin{tabular}{|c|c|c|c|}
\hline & SDH Mutation-Positive & SDH Mutation-Negative & $P$ Value \\
\hline No. of lesions & 30 & 18 & NA \\
\hline Sex (male/female) & 7:16 & $2: 15$ & .37 \\
\hline Age (mean) (yr) & 43.9 (SD, 16.2) (23 patients) & 56.9 (SD, 10.7) (17 patients) & .007 \\
\hline Maximum diameter (median) (IQR) (mm) & $26.5(20.6-33.0)$ & $24.4(21.2-36.0)$ & .68 \\
\hline Salt-and-pepper appearance & $24 / 30$ & $13 / 18$ & .72 \\
\hline Ratio of head/neck region & $13: 17$ & $13: 5$ & .07 \\
\hline Adjacent osseous erosive changes of head region & $13: 13$ & $12: 13$ & 1 \\
\hline Necrotic or cystic changes & $18 / 30$ & $10 / 18$ & .77 \\
\hline
\end{tabular}

Note:-NA indicates not applicable; IQR, interquartile range.

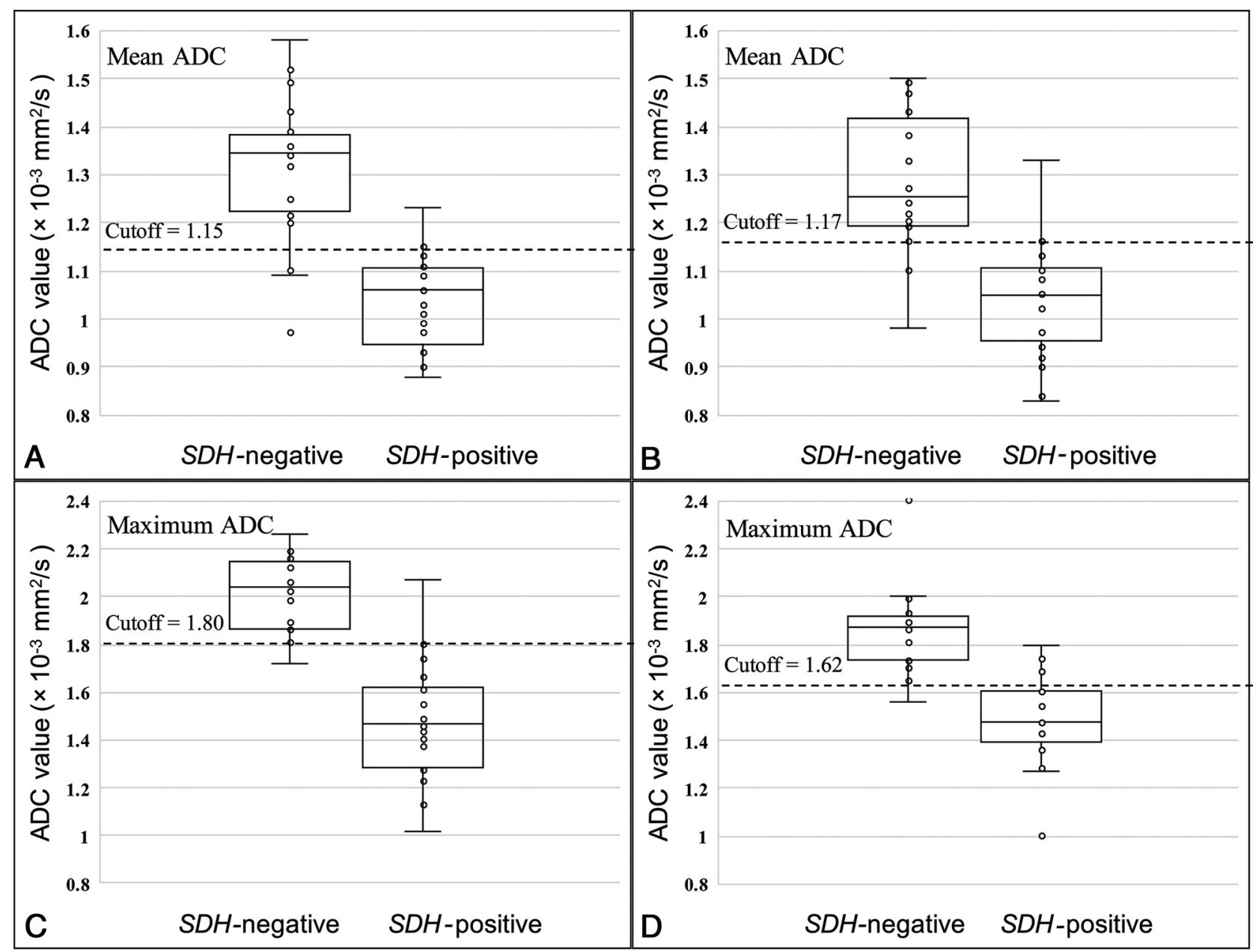

FIG 2. Comparison of mean and maximum ADC values between the $S D H$ mutation-negative group and the SDH mutation-positive group $(A$ and $C$, result of reader $1 ; B$ and $D$, result of reader 2 ).

$\left.0.16] \times 10^{-3} \mathrm{~mm}^{2} / \mathrm{s} ; P<.001\right), \mathrm{nADC}_{\text {mean }}(1.40$ [SD, 0.33] versus 1.73 [SD, 0.22]; $P<.001)$, and $\mathrm{nADC}_{\text {maximum }}(1.95$ [SD, 0.37] versus 2.64 [SD, 0.22]; $P<.001$ ) were significantly lower in the $S D H$ mutation-positive group than in $S D H$ mutation-negative group (Online Supplemental Data and Fig 2A,-C). The size of the ROI was 313 (SD, 259) $\mathrm{mm}$.

\section{Reader 2 Results}

$\mathrm{ADC}_{\text {mean }}\left(1.04[\mathrm{SD}, 0.12]\right.$ versus $1.30[\mathrm{SD}, 0.20] \times 10^{-3} \mathrm{~mm}^{2} / \mathrm{s}$; $P<.001), \mathrm{ADC}_{\text {maximum }}(1.49[\mathrm{SD}, 0.20]$ versus 1.87 [SD, $\left.0.20] \times 10^{-3} \mathrm{~mm}^{2} / \mathrm{s} ; P<.001\right), \mathrm{nADC}_{\text {mean }}(1.37$ [SD, 0.16] versus 1.74 [SD, 0.27]; $P<.001$ ), and $\mathrm{nADC}_{\text {maximum }}$ (1.97 [SD, 0.27] versus 2.48 [SD, 0.28]; $P<.001)$ were significantly lower in the $S D H$ mutation-positive group than in $S D H$ mutation-negative group (Online Supplemental Data and Fig 2B, $-D$ ). The size of the ROI was 291 (SD, 229) mm.

There were no significant statistical differences in $\mathrm{ADC}_{\text {minimum }}$ and $\mathrm{nADC}_{\text {minimum }}$ data for both readers. Representative cases of an $S D H$ mutation-positive paraganglioma and an $S D H$ mutationnegative paraganglioma are shown in Figs 3 and 4, respectively. 

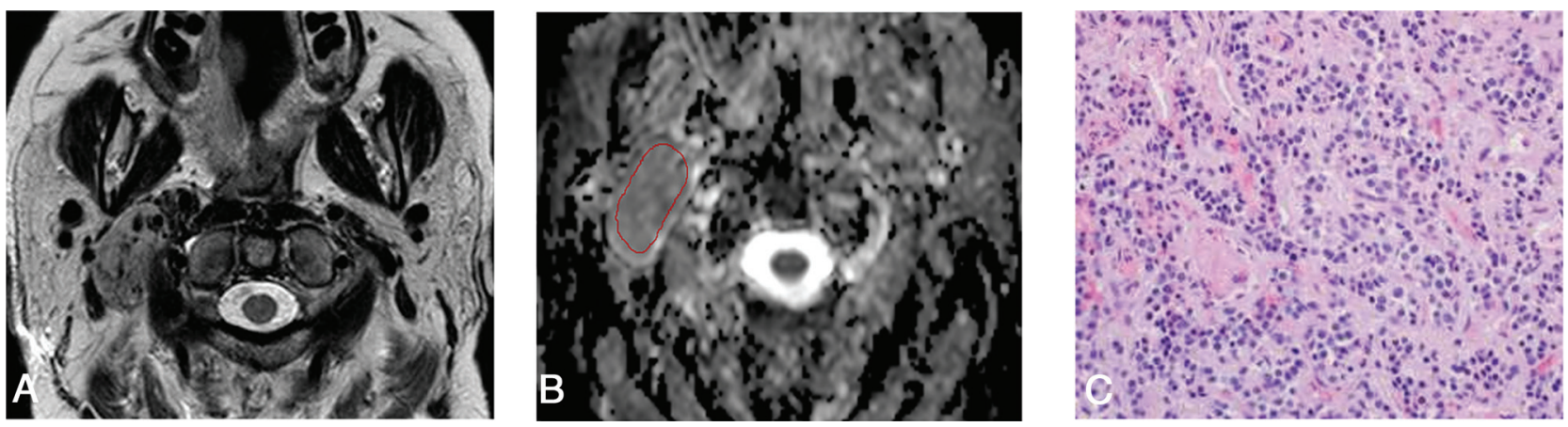

FIG 3. A 62-year-old woman negative for the SDH mutation with a paraganglioma in the right carotid space. A, Axial T2-weighted image demonstrates a heterogeneous well-defined tumor with flow voids in the right carotid space. $B$, The freehand ROI is placed on the lesion on the ADC map. Mean ADC, maximum ADC, and minimum ADC values of reader 1 are $1.31,1.61$, and $0.71 \times 10^{-3} \mathrm{~mm}^{2} / \mathrm{s}$, respectively. $C$, The resection specimen shows chief cells forming variable-size clusters in the zellballen pattern (H\&E, $\times 40)$.
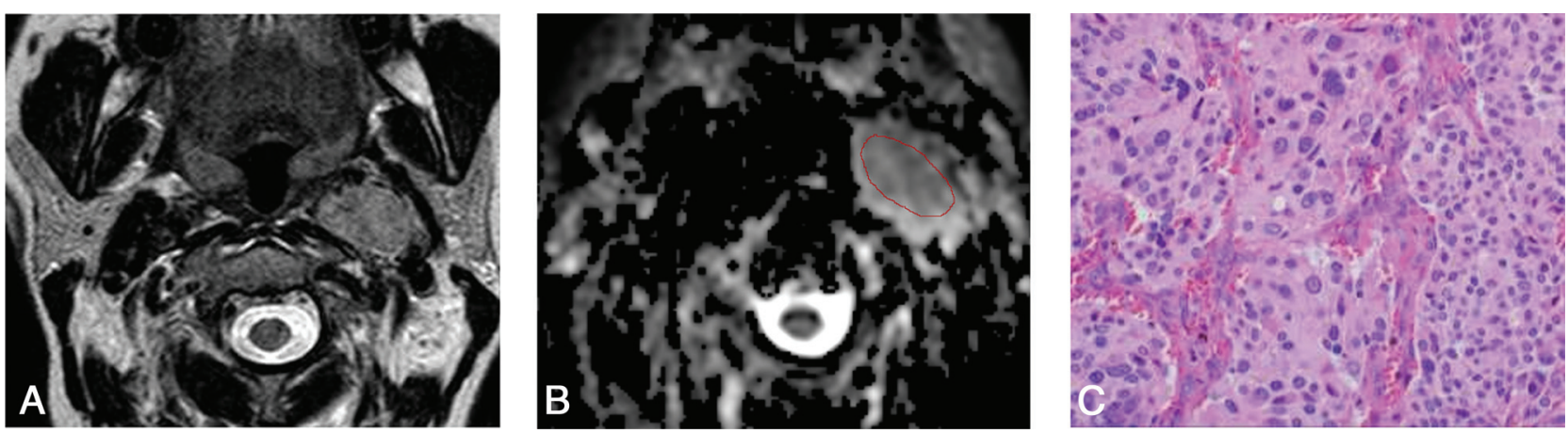

FIG 4. A 52-year-old woman positive for the SDHD mutation with a paraganglioma in the left carotid space. A, Axial T2-weighted image demonstrates a heterogeneous tumor with flow voids. $B$, The freehand ROI is placed on this lesion on the ADC map. The mean ADC, maximum ADC, and minimum $A D C$ of reader 1 are $1.13,1.57$, and $0.51 \times 10^{-3} \mathrm{~mm}^{2} / \mathrm{s}$, respectively. $C$, The resection specimen shows a large and irregular cell nest and prominent vascularity $(\mathrm{H} \& \mathrm{E}, \times 40)$.

Table 2 depicts the areas under the curve and diagnostic performances of the $\mathrm{ADC}_{\text {mean }}, \mathrm{ADC}_{\text {maximum, }} \mathrm{nADC}_{\text {mean }}$, and $\mathrm{nADC}_{\text {maximum }}$ for both readers.

Interreader agreement for tumor characteristics was substantial-to-almost perfect $(\kappa=0.625-1)$.

\section{DISCUSSION}

Our study aimed to evaluate the utility of ADC values and tumor characteristics on CT and MR imaging in differentiating SDH mutation-positive versus mutation-negative head and neck paragangliomas. While the $S D H$ mutation could not be identified by tumor characteristics interpreted on the basis of conventional imaging features, ADC values were significantly different between the 2 cohorts, with the diagnostic performances of areas under the curves from 0.87 to 0.94 .

Prior studies focusing on ADC values in paragangliomas ${ }^{11,16,17}$ showed mean ADC values ranging between $0.89 \times 10^{-3}$ and $1.30 \times 10^{-3} \mathrm{~mm}^{2} / \mathrm{s}^{11,16}$ Our study revealed mean ADC values of 1.07/1.04, 1.31/1.30, and 1.16/1.17 $\times 10^{-3}$ $\mathrm{mm}^{2} / \mathrm{s}$ for $S D H$ mutation-positive, mutation-negative, and total paragangliomas; thus, the relatively wide range of $\mathrm{ADC}$ values reported in past literature may be due to differences in the proportion of $S D H$ mutations in the study populations.
In our study, the mean and maximum ADC values of the $S D H$ mutation-positive group were significantly lower than those of $S D H$ mutation-negative group. It has been recognized that paragangliomas show different tumor cell morphology and cellularity and various histologic patterns, such as nests of tumor cells separated by peripheral capillaries (zellballen pattern) or large and irregular cell nest patterns. ${ }^{12}$ This histopathologic background may result in lower mean and maximum $\mathrm{ADC}$ values in the $S D H$ mutation-positive group. A histologic study suggested that no difference is to be expected in benign and malignant paragangliomas, ${ }^{18}$ but to the best of our knowledge, there have not been studies about pathologic differences based on SDH-mutation status. In another study, $S D H$ mutation-positive paragangliomas have been reported to show prominent vascularization. ${ }^{6}$ Prominent signal voids from higher arterial vascularity can result in T2 blackout on DWI and low ADC values within the highflow arteries, which could contribute to a decrease in the overall ADC values. ${ }^{19}$ Therefore, differences in vascularity between the $S D H$ mutation-positive group and the $S D H$ mutation-negative group may also result in differences of mean and maximum ADCs.

There was no significant difference in minimum ADC values between the 2 groups. This can be because paragangliomas have 
Table 2: Diagnostic performance of ADC values in differentiating groups positive for the $S D H$ mutation from those negative for it (both readers' results)

\begin{tabular}{lcccc}
\hline & $\begin{array}{c}\text { ADC }_{\text {Mean }}\left(\times 10^{-3}\right. \\
\left.\mathrm{mm}^{2} / \mathrm{s}\right)\end{array}$ & $\begin{array}{c}\mathrm{ADC}_{\text {Maximum }}\left(\times 10^{-3}\right. \\
\left.\mathrm{mm}^{2} / \mathrm{s}\right)\end{array}$ & nADC $_{\text {Mean }}$ & nADC $_{\text {Maximum }}$ \\
\hline Cutoff & $1.15 / 1.17$ & $1.80 / 1.62$ & $1.52 / 1.53$ & $2.32 / 2.07$ \\
Sensitivity & $0.90 / 0.95$ & $0.93 / 0.79$ & $0.90 / 0.95$ & $0.93 / 0.68$ \\
Specificity & $0.83 / 0.78$ & $0.94 / 0.94$ & $0.83 / 0.83$ & $0.94 / 1.00$ \\
PPV & $0.90 / 0.82$ & $0.97 / 0.94$ & $0.90 / 0.86$ & $0.97 / 1.00$ \\
NPV & $0.83 / 0.93$ & $0.90 / 0.81$ & $0.83 / 0.94$ & $0.90 / 0.75$ \\
Accuracy & $0.88 / 0.87$ & $0.94 / 0.87$ & $0.88 / 0.89$ & $0.94 / 0.84$ \\
AUC & $0.87 / 0.91$ & $0.94 / 0.94$ & $0.87 / 0.91$ & $0.94 / 0.94$ \\
\hline
\end{tabular}

Note:-PPV indicates positive predictive value; NPV, negative predictive value; AUC, area under the curve.

but were diagnosed on the basis of accepted and established diagnostic tests such as elevated plasma or urinary fractionated metanephrines and findings of head and neck CT and MR imaging and PET with 2-Deoxy-2$\left[{ }^{18} \mathrm{~F}\right]$ fluoro-d-glucose integrated with CT and ${ }^{111}$ In pentetreotide SPECT. ${ }^{1,4,22,23}$ Therefore, we believe that despite lack of histopathologic evidence, the diagnosis of paraganglioma was validated in all our patients. Last, we included multiple lesions from the

abundant arterial supply. We postulate that the very fast arterial flow in the lesion could show a signal void in both $b=1000$ and $b=0$ images, resulting in a very low value on the calculated ADC map, which affects the minimum ADC values. ${ }^{19}$ Moreover, in this study, there was no statistical difference in the presence of flow voids between the $S D H$ mutation-positive and $S D H$ mutation-negative groups.

Genetic testing is recommended for patients with paragangliomas who are diagnosed at a young age, have a family history, or demonstrate multifocal paragangliomas. Our results show that ADC values have high sensitivity and specificity in predicting $S D H$-mutation status, thereby suggesting that referring providers may be able to suggest close follow-up based on the ADC when genetic testing is not possible or feasible. Moreover, this result of ADC values may be useful in the early detection of $S D H$ mutations when patients who are SDH mutation-positive do not show the implication of the mutations such as young age, family history, and multiplicity. Early detection is important, especially in the case of $S D H B$ mutation, which is prone to malignant transformation. Clinicians can also suggest genetic testing to patients whose mean $\mathrm{ADC}$ values are low.

We chose to evaluate the ADC values on a single axial section instead of the entire tumor volume because prior studies using volumetric ADC analyses showed no better ability than singleaxial-section evaluations. ${ }^{20,21}$ The consistency between the results of both readers further supports the single-section method. Additionally, we normalized the ADC values of the tumors to those of the medulla oblongata to minimize variations due to differences in scan techniques or imaging platforms. The medulla is usually visualized within the FOV of head and neck imaging studies, and it is less affected by intrinsic signal abnormalities due to changes of chronic microvascular disease or direct tumor invasion. Given our strategy for standardization with ADC values of the medulla, we believe that our results are validated and robust.

Our study has several limitations. First, this was a retrospective study with a small cohort of patients from a single institution. This small cohort was due not only to the low incidence rate but also to the strict inclusion criteria of patients with genetic testing results. In our institution, genetic testing is currently recommended for patients who are suspected of hereditary paragangliomas, so prior probability of genetic mutation in our study population may be higher than that in the overall population of paragangliomas that have been reported before. Second, we also included the patients who were not evaluated histopathologically same patients. We believe that this is reasonable according to a previous study indicating that the $\mathrm{ADC}$ value and vascularity of paragangliomas may depend on the location of tumor. ${ }^{16}$

\section{CONCLUSIONS}

Our study shows that ADC values can be promising as a noninvasive imaging biomarker to predict $S D H$ mutation in head and neck paragangliomas.

\section{ACKNOWLEDGMENTS}

We thank Dr Jonathan McHugh, Department of Pathology, Division of Neuropathology, University of Michigan, for his assistance in reviewing the sections pertaining to the histopathology of the tumors.

\section{REFERENCES}

1. Withey SJ, Perrio S, Christodoulou D, et al. Imaging features of succinate dehydrogenase-deficient pheochromocytoma-paraganglioma syndromes. Radiographics 2019;39:1393-1410 CrossRef Medline

2. Williams MD, Rich TA. Paragangliomas arising in the head and neck: a morphologic review and genetic update. Surg Pathol Clin 2014;7:543-57 CrossRef Medline

3. Patel D, Phay JE, Yen TWF, et al. Update on pheochromocytoma and paraganglioma from the SSO Endocrine/Head and Neck Disease-Site Work Group, Part 1 of 2: advances in pathogenesis and diagnosis of pheochromocytoma and paraganglioma. Ann Surg Oncol 2020;27:1329-37 CrossRef Medline

4. Farrugia FA, Martikos G, Tzanetis P, et al. Pheochromocytoma, diagnosis and treatment: review of the literature. Endocr Regul 2017;51:168-81 CrossRef Medline

5. Neumann HP, Bausch B, McWhinney SR, et al. Germ-line mutations in nonsyndromic pheochromocytoma. N Engl J Med 2002;346:145966 CrossRef Medline

6. Williams MD. Paragangliomas of the head and neck: an overview from diagnosis to genetics. Head Neck Pathol 2017;11:278-87 CrossRef Medline

7. Offergeld C, Brase C, Yaremchuk S, et al. Head and neck paragangliomas: clinical and molecular genetic classification. Clinics (Sao Paulo) 2012;67:(Suppl 1):19-28 CrossRef Medline

8. Woolen S, Gemmete JJ. Paragangliomas of the head and neck. Neuroimaging Clin N Am 2016;26:259-78 CrossRef Medline

9. van Gils AP, van den Berg R, Falke TH, et al. MR diagnosis of paraganglioma of the head and neck: value of contrast enhancement. AJR Am J Roentgenol 1994;162:147-53 CrossRef Medline

10. Thoeny HC, De KF, King AD. Diffusion-weighted MR imaging in the head and neck. Radiology 2012;263:19-32 CrossRef Medline 
11. Aschenbach R, Basche S, Vogl TJ, et al. Diffusion-weighted imaging and ADC mapping of head-and-neck paragangliomas: initial experience. Clin Neuroradiol 2009;19:215-19 CrossRef Medline

12. Tischler AS, deKrijger RR. 15 years of paraganglioma: pathology of pheochromocytoma and paraganglioma. Endocr Relat Cancer 2015;22:123c33 CrossRef Medline

13. Srinivasan A, Dvorak R, Perni K, et al. Differentiation of benign and malignant pathology in the head and neck using 3T apparent diffusion coefficient values: early experience. AJNR Am J Neuroradiol 2008;29:40-44 CrossRef Medline

14. Koontz NA, Wiggins RH 3rd. Differentiation of benign and malignant head and neck lesions with diffusion tensor imaging and DWI. AJR Am J Roentgenol 2017;208:1110-15 CrossRef Medline

15. Landis JR, Koch GG. The measurement of observer agreement for categorical data. Biometrics 1977;33:159-74 CrossRef Medline

16. Güneş A, Ozgen B, Bulut E, et al. Magnetic resonance and diffusion weighted imaging findings of head and neck paragangliomas. Acta Oncologica Turcica 2019;52:416-23 CrossRef

17. Yuan Y, Shi H, Tao X. Head and neck paragangliomas: diffusion weighted and dynamic contrast enhanced magnetic resonance imaging characteristics. BMC Med Imaging 2016;16:12 CrossRef Medline
18. Feng N, Zhang WY, Wu XT. Clinicopathological analysis of paraganglioma with literature review. World J Gastroenterol 2009;15:3003-08 CrossRef Medline

19. Hiwatashi A, Kinoshita T, Moritani T, et al. Hypointensity on diffusionweighted MRI of the brain related to T2 shortening and susceptibility effects. AJR Am J Roentgenol 2003;181:1705-09 CrossRef Medline

20. Ahlawat $\mathrm{S}$, Khandheria $\mathrm{P}$, Grande $\mathrm{FD}$, et al. Interobserver variability of selective region-of-interest measurement protocols for quantitative diffusion weighted imaging in soft tissue masses: comparison with whole tumor volume measurements. J Magn Reson Imaging 2016;43:446-54 CrossRef Medline

21. Han X, Suo S, Sun Y, et al. Apparent diffusion coefficient measurement in glioma: influence of region-of-interest determination methods on apparent diffusion coefficient values, interobserver variability, time efficiency, and diagnostic ability. J Magn Reson Imaging 2017;45:722-30 CrossRef Medline

22. Chang CA, Pattison DA, Tothill RW, et al. Ga-DOTATATE and (18)F-FDG PET/CT in paraganglioma and pheochromocytoma: utility, patterns and heterogeneity. Cancer Imaging 2016;16;68:22 CrossRef Medline

23. Telischi FF, Bustillo A, Whiteman ML, et al. Octreotide scintigraphy for the detection of paragangliomas. Otolaryngol Head Neck Surg 2000;122:358-62 CrossRef Medline 